\title{
Clinical Profile and Management Option of Fibroid Uterus Patient
}

\author{
Muslina Akhter ${ }^{*}$ \\ A Salam ${ }^{2}$ \\ Khairul Anwar ${ }^{3}$ \\ Monirul Alam ${ }^{3}$ \\ Asma Kabir Shoma ${ }^{4}$ \\ Md Salim
}

\author{
'Department of Obstetrics \& Gynaecology \\ International Islamic Medical College \\ Chittagong, Bangladesh.

\section{${ }^{2}$ Department of Urology \\ Cox's Bazar Medicla College} \\ Cox's Bazar. \\ ${ }^{3}$ Department of Anaesthesiology \\ International Islamic Medical College \\ Chittagong, Bangladesh \\ ${ }^{4}$ Department of Physiology \\ International Islamic Medical College \\ Chittagong, Bangladesh. \\ ${ }^{5}$ Department of Surgery \\ International Islamic Medical College \\ Chittagong, Bangladesh.
}

\begin{abstract}
Background: Fibroids are the most common benign tumours of smooth muscle cells of uterus in females and typically found during the middle and later reproductive years. As fibroid is an estrogen and progesterone dependent tumour, it gradually decreases in size during starting of menopause. The objective of this presented study was to determine management options among fibroid uterus patients. Methods: 50 number of patients were included in this study those who's age of 20-55, with symptomatic uterine fibroid and undergone hysterectomy or myomectomy. Postmenopausal, Pregnancy and Asymptomatic fibroid were excluded from this study. Results: The study showed that 52 percent of patient having fibroid uterus were belonged to $31-40$ years of age. The mean age was $41.2 \pm 6.07$. The majority $74 \%$ of patients in this study presented with menstrual abnormalities, $40 \%$ presented with abdominal lump. Dysmenorrhoea was $26 \%, 6 \%$ patient had primary subfertility and $14 \%$ secondary subfertility. Total Abdominal Hysterectomy (TAH) with unilateral salpingo- oophorectomy done in $10 \%$ cases, TAH with bilateral salpinooophorectomy in $22 \%$ cases, non descent vaginal hysterectomy in $6 \%$ cases, myomectomy done in $20 \%$ cases and polypectomy was done in $2 \%$ cases. Conclusion: Uterine fibroids are very common in women and frequently in late reproductive and perimenopausal years. It is also a common gynecological problem in our country, which frequently disturbs the lives of woman. Women now have choice of therapies for the treatment of fibroids.
\end{abstract}

Key words: Fibroids; Clinical profile; Management option; TAH.

\section{INTRODUCTION}

Fibroids are the most common benign tumours of smooth muscle cells of uterus in females and typically found during the middle and later reproductive years ${ }^{1,2}$.

The incidence of uterine fibroid tumours increase as woman grow older and they may occur in more than 30 percent of woman 40 to 60 years of age ${ }^{3}$.

Woman with fibroids can be asymptomatic or may present with menorrhagia, pelvic pain with or without dysmenorrhoea or pressure symptoms, subfertility and recurrent pregnancy loss ${ }^{4}$. Symptoms depend on the location of the lesion and its size. During pregnancy they may be the cause of miscarriage, bleeding, premature labor, or interference with the position of the fetus ${ }^{5}$. They are not a typical cause for infertility. But when a fibroid is located in submucosal position and it is thought that this location may interfere with the function of lining and the ability of the embryo to implant ${ }^{6}$.

Fibroids lead to heavy vaginal bleeding lead to anemia and iron deficiency. Fibroids may also present alongside endometriosis, which itself may cause infertility. Adenomyosis may be mistaken for or coexist with fibroids. In very rare cases, malignant growth, leiomyosarcoma can develop ${ }^{7}$. Leiomyoma are more common in obese woman. Fobroids are dependent on estrogen and progesterone to grow and therefore relevant only during the reproductive years, they are expected to shrink after menopause ${ }^{8}$. 
Fibroids are monoclonal tumours, approximately 40 to $50 \%$ show karyotypically detectable chromosomal abnormalities, when multiple fibriods are present they can have unrelated genetic defects. Genetic predispositions, prenatal hormone exposure and the effects of hormones, growth factors and xenoestrogens cause fibroid growth. Fibroid growth is strongly dependent on estrogen and progestrone ${ }^{9}$.

Treatment options include expectant management, medical therapy, hysterectomy, myomectomy, uterine artery embolization, myolysis. Treatment must be individualized based on such consideration as the presence and severity of symptoms, the patient desire for definitive treatment, the desire to preserve childbearing capacity, the importance of uterine preservation, infertility related to uterine cavity distortions and previous pregnancy complications related to fibroid tumours ${ }^{3}$.

Few studies had been cited to determine the clinical profile and management option of fibroid uterus among the patients attending at hospital. The objective of this presented study was to determine management options among fibroid uterus patients.

\section{MATERIALS \& METHODS}

This presented study was prospective cross sectional study, conducted in the Department of Obstetrics and Gynaecology, Bangabandhu Sheikh Mujib Medical University (BSMMU), Dhaka. The study population had taken from admitted patient in BSMMU with fibroid uterious. 50 number of patients were included in this study those who's age of 20-55, with symptomatic uterine fibroid and undergone hysterectomy or myomectomy. Postmanopausal, Pregnancy and Asymptomatic fibroid were excluded from this study. The main outcomes of study were age, parity, menstrual disturbance, management option contraceptive history. Data were collected in a predesigned form. No data or any information was collected without permission of patient, participation in this research was fully voluntary.

All data were analyzed by using computer based Statistical Package for Social Science (SPSS 16) programmed. Statistical analysis was performed, categorical variables was presented in the form of frequency and percentage. Quantitative data were presented in the form of mean and standard deviation.

\section{RESULTS}

The study showed that 52 percent of patient having fibroid uterus were belonged to $31-40$ years of age. The mean age was $41.2 \pm 6.07$ (Table 1). The majority of patients were in para 1-2 group when parity of patient divided into 4 groups. Only 10 percent of patients were in para 0 group. Out of these patients, 4 patients had 1 abortion, 1 patient had 2 abortion and 3 patients had primary subfertility (Table 2) $64 \%$ patients used contraception, among them $16 \%$ used barrier method, $16 \%$ used oral pill, $14 \%$ had tubectomy and only $8 \%$ had taken injectable contraceptive (Table 3 ). Positive family history was found $18 \%$ (Table 4). The majority $74 \%$ of patients in this study presented with menstrual abnormalities, $40 \%$ presented with abdominal lump. Dysmenorrhoea was $26 \%, 6 \%$ patient had primary subfertility and $14 \%$ secondary subfertility (Table 4 ).
USG finding of this study were found that $98 \%$ of fibroid located in body of the uterus. Cystic ovary was found $8 \%$, chocolate cyst was $4 \%$ and endometrial hyperplasia 6\% (Table 6). Total Abdominal Hysterectomy (TAH) was done in $40 \%$ cases. TAH with unilateral salpingo- oophorectomy done in $10 \%$ cases, TAH with bilateral salpino-oophorectomy in $22 \%$ cases, non descent vaginal hysterectomy in $6 \%$ cases, myomectomy done in $20 \%$ cases and polypectomy was done in $2 \%$ cases (Table 7 ).

Table 1: Age distribution of the study patient $(n=50)$

\begin{tabular}{ccr} 
Age & Number of Patients & Percentage \\
$\leq 20$ & 0 & 0.0 \\
$21-30$ & 3 & 6.0 \\
$31-40$ & 26 & 52.0 \\
$41-50$ & 20 & 40.0 \\
$\geq 50$ & 1 & 2.0 \\
Mean \pm SD & & $41 \pm 6.07$ \\
Range (min-max) & & $(22-51)$ \\
\hline
\end{tabular}

Table 2 : Parity of the patients $(n=50)$

$\begin{array}{rcc}\text { Para } & \text { Number of Patients } & \text { Percentage } \\ 0 & 5 & 10.0 \\ 1-2 & 21 & 42.0 \\ 3-4 & 18 & 36.0 \\ >4 & 6 & 12.0\end{array}$

Table 3 : Contraceptive history $(\mathrm{n}=50)$

Contraceptive history Number of Patients Percentage

$\begin{array}{lrr}\text { No contraception } & 18 & 36.0 \\ \text { Natural methods } & 4 & 8.0 \\ \text { Barrier method } & 8 & 16.0 \\ \text { Oral pill } & 8 & 16.0 \\ \text { I.U.C.D } & 1 & 2.0 \\ \text { Injectable } & 4 & 8.0 \\ \text { Tubectomy } & 7 & 14.0\end{array}$

Table 4 : Family history $(n=50)$

\begin{tabular}{lcc} 
Family history & Number of Patients & Percentage \\
Present & 9 & 18 \\
Absent & 41 & 82 \\
\hline
\end{tabular}

Table 5 : Presenting symptoms $(\mathrm{n}=50)$

$\begin{array}{lcc}\text { Symptoms \& Sign } & \text { Number of Patients } & \text { Percentage } \\ \text { Menstrual disturbances } & 37 & 74.0 \\ \text { Normal menstruation } & 13 & 26.0 \\ \text { Abdominal lump } & 20 & 40.0 \\ \text { Pain in lower abdomen } & 7 & 14.0 \\ \text { Dysmenorrhoea } & 13 & 26.0 \\ \text { Infertility } & & \\ \quad \text { Primary } & 3 & 6.0 \\ \quad \text { Secondary } & 7 & 14.0 \\ \text { Urinary frequency } & 7 & 14.0 \\ \text { Dyspareunia } & 6 & 12.0\end{array}$


Table 6 : USG finding $(\mathrm{n}=50)$

\begin{tabular}{lcc} 
USG finding & Number of Patients & Percentage \\
Location of fibroid & & \\
Body & 49 & 98.0 \\
Cervix & 1 & 2.0 \\
Cystic ovary & 4 & 8.0 \\
Chocolate cyst & 2 & 4.0 \\
Endometrial hyperplasia & 3 & 6.0 \\
\hline
\end{tabular}

Table 7 : Types of surgical management had done $(n=50)$

$\begin{array}{lcc}\text { Surgical management } & \text { Number of Patients } & \text { Percentage } \\ \text { TAH } & 20 & 40.0 \\ \begin{array}{l}\text { TAH with unilateral } \\ \text { salpingo-oophorectomy }\end{array} & 5 & 10.0 \\ \begin{array}{l}\text { TAH with bilateral } \\ \text { salpingo-oophorectomy }\end{array} & 11 & 22.0 \\ \begin{array}{l}\text { Non descent vaginal } \\ \text { hysterectomy }\end{array} & 3 & 6.0 \\ \begin{array}{l}\text { Myomectomy } \\ \text { Polypectomy }\end{array} & 10 & 20.0 \\ & 1 & 2.0\end{array}$

\section{DISCUSSION}

This prospective cross sectional study was carried out with an aim to determine management option, clinical presentation and the risk factors in woman with fibroid uterus. The present study finding were discussed and compared with previously published relevant studies.

In this study we found the mean age of patient was $41.2 \pm 6.02$ years with range from 22 to 51 years and more than half $(52 \%)$ of the patient was in $4^{\text {th }}$ decade. This results are closely resemble with other studies ${ }^{10,11}$.

It was observed that majority $(42 \%)$ of the patients were in para 1-2 group, 5 (10\%) of patient were in nullipara group, out of these patients, 4 patients had 1 abortion, 1 patient had 2 abortion and 3 patient had primary subfertility. The incidence of fibroids uterus is more in less parity. Fibroid uterus was predominant in parity 2 and decline with increased parity. Furthermore, nearly all epidemiologic studies had showed an inverse association between parity and fibroids, suggestive of a protective effect $^{12,13}$.
The effect of Oral Contraceptive Pill (OCP) on risk of fibroids is controversial. Whatever the trend, these reports indicate that the risk is dependent on duration of OCP use and dose of the sex steroids with a direct association in some studies and inverse association in others ${ }^{14}$. In this study two third of the patients $(64.0 \%)$ used contraception. It was observed that almost three fourth $(74 \%)$ of the patients presented with menstrual abnormalities, $40 \%$ presented with abdominal lump that is similar to other study ${ }^{15}$.

The surgical treatments were offered to the entire patient. Most of the patients had completed their family so total abdominal hysterectomy with preservation of both ovaries or with unilateral or bilateral salpingo-oophorectomy was done in $80 \%$ cases, which is comparable with other studies in our country. Newer technique include the use of laser vaporization, ultrasonic diathermy coagulation to burn the fibroid nodules, and laparoscopic myomectomy for abdominal myomectomy mentioned $^{16}$.

\section{CONCLUSION}

This study was undertaken to determine management options among fibroid uterus patients. Uterine fibroids are very common in women and frequently in late reproductive and perimenopausal years. It is also a common gynecological benign tumour in our country, which frequently disturbs the lives of woman. Women now have choice of therapies for the treatment of fibroids. Increasingly they are requesting to choose their mode of treatment and the gynecologist can give a woman other choices apart from surgery for the treatment of this disease.

\section{DISCLOSURE}

All the authors declared no competing interest. 


\section{REFERENCES}

1. Neiger R, Sonek J, Croom C, Ventolini G. Pregnancy related changes in the size of uterine leiomyomas. The journal of reproductive medicine. 2006;51(9): 671-674.

2. Buttram V C , Reiter RC. Uterine leiomyomata: etiology, symptomatology and management. Fertil Steril.1981;6: 433-445.

3. Manor C, Brunsell MS. Uterine fibroid tumours: Diagnosis and treatment. Am Fam Physician. 2007; 75(10):1503-1508.

4. Lumsden M A , Wallace E M. Clinical presentation of uterine fibroids. Baillieres Clin Obstet Gyne. 1998;12(2): 177-195.

5. Conforth T . Benign uterine fibroid tumours. About com health's disease and condition content. 2009.

6. American Society of Reproductive Medicine Patient Booklet: Uterine Fibroids. 2003.

7. Wallach EE, Vlahos NF. Uterine myomas : an overview of development, clinical feature and management. Obstet G. 2004;104:393406.

8. Wise L A, Palmer J R, Spiegelman D et al. Influence of body size and body fat distribution on risk of uterine leiomyomata in US black woman. Epidemiology. 2005;16:346-354.

9. Okolo S. Incidence, etiology, and epidemiology of uterine fibroids. Best practice \& research clinical obstetrics and Gynaecology. 2008;22(4): 571-588.

10. Zhang S, Chen WZ, Liu YJ, Hub X et al. Feasibility of magnetic resonance imaging-guided high intensity focused ultrasound therapy for ablating uterine fibroids in patients with bowel lies anterior to uterus. European Journal of Radiology. 2010;73:396.

11. Coronado GD, Marshall LM and Schwart SM. Complication in pregnancy, labor and Delivery with Uterine Leiomyomas: A Population - Based Study. Obstet Gynecol. 2000;95:764-769.

12. Samadi AR, Leem NC, Flanders D et al. Risk factors for self-reported uterine fibroids: a case control study. Am J Public Health. 1996;86: 858

13. Sato F, Miyake H, Nishi M, Kudo R. Fertility and Uterine size among Asian woman undergoing hysterectomy for leiomyomas. Int J Fertil. 2000.

14. Friedman AJ, and Thomas. Does low dose combination oral contraceptive use affect uterine size or menstrual flow in premenopausal woman with leiomyomas? Ostat Gyneco. 1995;85:631.

15. Begum J . Clinical presentation of leiomyoma of uterus ( Dissertation). Dhaka BCPS. 1997.

16. Lumsden M A. Benign disease of uterus in Dewhurst's Textbook of Obst and Gyn. 2007;7:636. 